\title{
Recent Advances and History of Vitreous Surgery
}

\author{
Tatsuya Mimura, MD ${ }^{1,2^{*}}$ Takayuki Nakashizuka, $\mathbf{M D}^{2}$ Mikiro Mori, MD $^{\mathbf{2}}$ \\ ${ }^{1}$ Department of Ophthalmology, University of Tokyo Graduate School of Medicine, \\ Tokyo, Japan. \\ ${ }^{2}$ Department of Ophthalmology, Toranomon Hospital, Tokyo, Japan.
}

Submitted March 2011. Accepted August 2011.

\begin{abstract}
There have been tremendous advances in the small-gauge pars plana vitrectomy (PPV) systems. This review provides an overview of the recent advances and state of the art of vitreous surgery. The two most innovative advancements that have been developed in this area are the small-gauge cutter and the new illuminating systems. Compared to the traditional 20-gauge PPV, transconjunctival sutureless small-gauge PPV is a safe and effective strategy to treat a variety of vitreoretinal diseases. Chandelier illumination allows better visualisation of vitreous for bimanual surgery. The small-gauge PPV provides benefits in terms of less inflammation, less patient discomfort, and faster recovery of the visual acuity.
\end{abstract}

Keywords: small-gauge, pars plana vitrectomy, 25 gauge, illuminating systems, review

\section{INTRODUCTION}

The human vitreous body is a unique, spherical transparent structure that lies in the posterior segment of the eye. It is surrounded by the retina, pars plana, and the lens of the eye (Figure 1). The vitreous body is composed mainly of collagen, hyaluronic acid, and water. Changes in the vitreous structure with aging can cause vitreous liquefaction, vitreous detachment, and vitreoretinal diseases such as epiretinal membrane, macular hole, and incidental vitreoretinal hemorrhage. As these various vitreoretinal diseases can lead to severe visual impairment, vitreous surgery is commonly performed to remove the vitreous, which helps patients regain their vision.

The origins of vitreous surgery can be traced back to the early 1970s. Machemer first introduced pars plana vitrectomy (PPV) using a 17-gauge (17-G) cutter [1, 2]. Subsequently, O'Malley and Heintz introduced a three-port 20-G canular entry system in 1975 [1, 2], while De Juan introduced 25-G instruments in 1990 [4]. Over the last decade, 23-G [5, 6], 25-G [7-9], and 27-G [10, 11] transconjunctival sutureless vitrectomy devices were introduced and used to treat patients. The continual advances in both the technology and instrumentation have resulted in reductions in the incision size and led to a more rapid stabilization of the wound.

\footnotetext{
${ }^{*}$ Corresponding author: Tatsuya Mimura, MD, Ph.D, Department of Ophthalmology, University of Tokyo Graduate School of Medicine, 7-3-1 Hongo, Bunkyo-ku, Tokyo, 113-8655 Japan. Phone: +81 35800-5108 (Ex33503), Fax: +81 33817-0798, E-mail: mimurat-tky@umin.ac.jp. Other authors: nak777@ hotmail.co.jp; mikiro-mori@umin.net.
} 


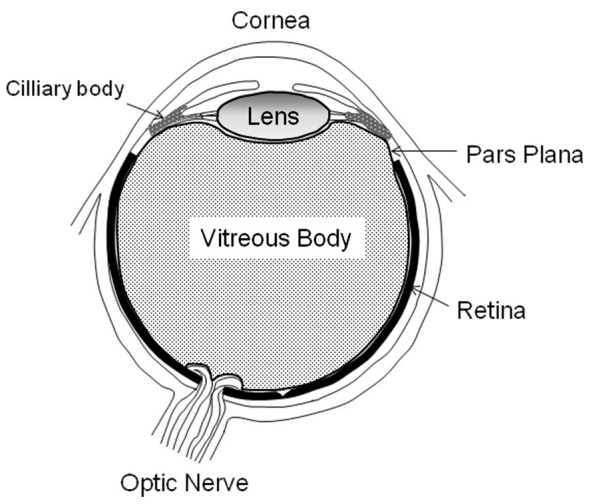

Figure 1. The structure of the eye. The vitreous is a transparent jelly-like tissue within the eye that occupies the space between the lens and the retina, and the light-sensitive layer at the back of the eye. The vitreous is $99 \%$ water, with the remaining $1 \%$ consisting of collagen, hyaluronic acid and ions.

Recent innovations in vitreous surgery (Figure 2), including light amplification, widefield viewing systems, and illumination systems, have made it easier to treat vitreoretinal diseases that were previously difficult or even impossible to treat [12-17]. The current review is based on recent reports and reviews obtained from the Medline database, industry literature, personal communications, and personal experience. The aim of this paper is to provide a comprehensive review of the latest advances in vitreous surgery.

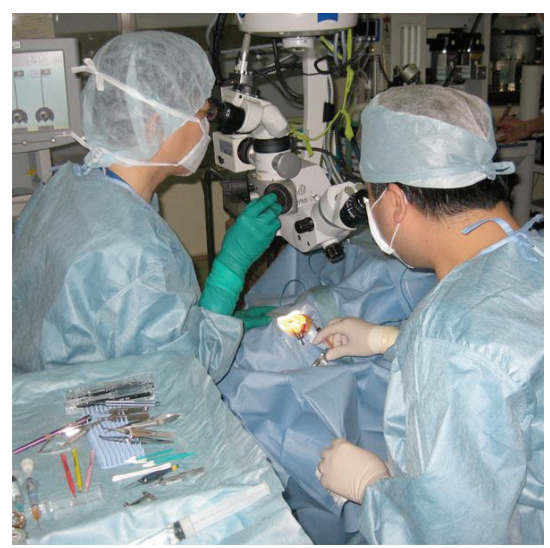

Figure 2. Two surgeons performing a vitreous surgery at Toranomon Hospital. The 25 -gauge and other microsurgical instruments used in the surgery are shown on the standard operating table. 


\section{HISTORY OF PARS PLANA VITRECTOMY SURGERY}

Machemer developed and introduced the first pars plana vitrectomy procedure. His method featured a single port $17-\mathrm{G}(1.5 \mathrm{~mm}$ diameter $)$ multifunctional instrument that was capable of cutting and aspirating the vitreous $[1,2]$. Such $17-\mathrm{G}$ multifunctional instrument helped to improve the success rates of vitreoretinal disease treatments. The instrument consisted of a micromotor to drive a rotating cutting mechanism at the tip of the vitreous cutter, along with suction and infusion systems. Therefore, the device was referred to as the VISC (vitreous infusion suction cutter) [18]. The device was able to excise formed vitreous, while simultaneously replacing the vitreous volume with an infusion of saline solution. The intraocular portion of the vitreous cutter had a relatively large outside diameter of $2.3 \mathrm{~mm}$, and a fiber optic sleeve that could be attached to the instrument tip in order to provide intraocular illumination. However, to ensure continuous vitreous suction, an assistant often had to draw on a syringe which sometimes caused operative complications.

In 1975, O’Malley introduced a three-port 20-G canular entry system that employed a smaller vitreous $20-\mathrm{G}(0.9 \mathrm{~mm})$ cutter [3]. This three-port pars plana vitrectomy soon became the standard of care for modern vitreous surgery. Sclerotomies that use the 20$\mathrm{G}$ vitrectomy technique require both the sclerotomy sites and the overlying conjunctiva to be closed with sutures. Although the guillotine style probe that was initially used for the early $20-\mathrm{G}$ cutter was very small, eventually it proved to be entirely unsatisfactory due to inherent problems in cutting the vitreous, and high cost. Also, the non-disposable probes used with this device required complete pre-operative sterilization and needed close care after each operation. To solve these problems, a disposable spring type 20-G vitreous cutter was developed in the early 1980s. Shortly after this, various companies developed the next generation of the 20-G cutter and vitrectomy systems, including the Microvit ${ }^{\circledR}$ (Storz Instruments, St. Louis, MO), Accurus ${ }^{\circledR}$ (Alcon Labs, Fort Worth, TX) and Millennium ${ }^{\circledR}$ (Bausch \& Lomb, Rochester, NY) machines (Figure 3).

In 1990, de Juan and Hickingbotham developed a 25-G (0.5 mm diameter) vitrectomy system based on conventional sclerotomy methods. However, this system still required to suture the sclerotomy sites [4]. Over the last decade, modern transconjunctival sutureless $23-\mathrm{G}$ and $25-\mathrm{G}$ vitrectomy systems were introduced. Fujii et al. introduced the $25-\mathrm{G}$ transconjunctival sutureless vitrectomy (25G TSV) system in 2002 [7-9], which was commercialized by Bausch \& Lomb in 2001 as the Millennium $^{\mathrm{TM}}$ Transconjunctival Sutureless Vitrectomy System (TSV25). This was followed by Hilton and Eckhart's introduction of a 23-G system, which combined some of the benefits from both the 25- and 20-G instrumentation packages [5, 6]. Oshima et al. developed a self-retaining $27-\mathrm{G}$ instrument system that included an infusion line, a high-speed vitreous cutter, an illumination system, and a variety of vitreoretinal instruments, such as membrane forceps and sharp-tipped endophotocoagulation probes $[10,11]$. 
A

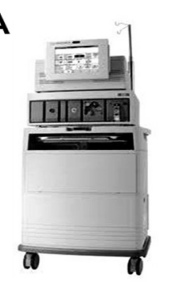

B

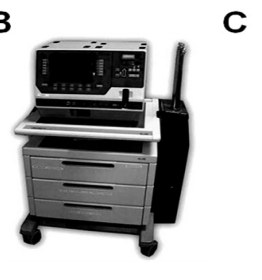

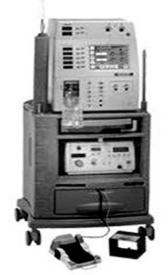

Figure 3. Vitrectomy machines. (A) Millennium ${ }^{\circledR}$ (Bausch \& Lomb), (B) Microvit Vitrectomy System ${ }^{\circledR}$ (Storz Instruments), and (C) Accurus ${ }^{\circledR}$ (Alcon Surgical). Each of the machines is able to perform the following basic functions: aspiration, cutting, infusion, endoillumination, and gas-vented technology.

\section{VITREOUS CUTTER}

While the sclerotomies performed in the $20-\mathrm{G}$ vitrectomies were $0.9 \mathrm{~mm}$ in diameter, the sclerotomies in $23-\mathrm{G}$ and $25-\mathrm{G}$ vitrectomies are only $0.65 \mathrm{~mm}$ and $0.5 \mathrm{~mm}$ in diameter, respectively. Due to the smaller inner diameter and port sizes, the 23- and 25$\mathrm{G}$ vitrector has a lower aspiration and infusion rate as compared to the $20-\mathrm{G}$ vitrector. Although lower cutting rates can cause vitreoretinal traction, thereby damaging the retina, the $25-\mathrm{G}$ high-speed cutter with a very low aspiration flow of vitreous fluid may be more effective for dissecting the vitreous close to the retinal surface.

There are two types of vitreous cutters developed based on the VISC: the pneumatic cutter and the electrical cutter. The pneumatic vitreous cutter was first reported by O'Malley and Heintz in 1975 [3]. This pneumatic probe cutter is driven by an intermittent air discharge from a pneumatic energy source located in the surgical device (Figure 4A, B). Mechanical energy supplied by a remote unit causes air to force a rotational blade that cuts by rotating around its longitudinal axis (Figure 4C) or a vertical guillotine-like blade that cuts by longitudinal motion along its axis (Figure 4D) [3]. This widely adopted design makes it possible for the pneumatic cutters to be smaller and lighter than those cutters with an electric motor in the hand-piece, such as the Millennium TSV25 High-Speed Vitreous Cutter ${ }^{\mathrm{TM}}$ [19]. Electric probes employ a motor and cam mechanism to drive an inner tube. The constant sinusoidal motion of the inner tube produces an equal closed and open time that is independent of the cutting rates.

Advantages and disadvantages of the pneumatic and electrical cutters are listed in Table 1. According to Bausch \& Lomb, their high-speed vitrectomy electric cutter uses the TSV25 system, which at 1,500 cuts per minute (cpm) generates a 50\% higher aspiration flow than the $25-\mathrm{G}$ pneumatic cutters [19]. However, many vitreous surgeons prefer to use a pneumatic cutter simply because the pneumatic disposable cutters weigh much less than the electric cutters, thereby reducing fatigue. 
Table 1. Comparison between electric and pneumatic cutters

\begin{tabular}{lll}
\hline Power source & Advantage & Disadvantage \\
\hline Electric & $\begin{array}{l}\text { Cutter maintains a constant duty } \\
\text { cycle in a wide range of operating } \\
\text { speeds. }\end{array}$ & Cutter is heavy. \\
Pneumatic & Cutter is small and light. & $\begin{array}{l}\text { Cutter cannot maintain a high duty cycle as } \\
\text { the blade speed increases. }\end{array}$ \\
\hline
\end{tabular}

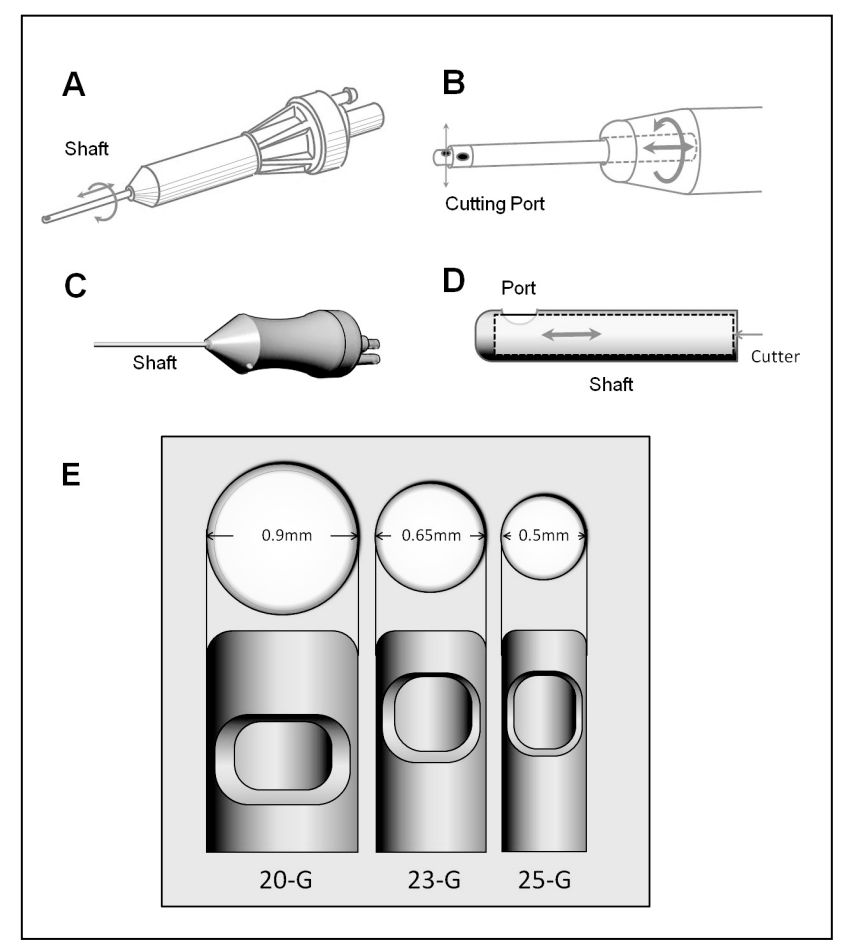

Figure 4. Vitreous cutters and comparison of the 20-, 23- and 25-gauge vitreous cutters. A, B: Original model of the 20-G Alcon ATOP Cutter (1987). The device has a tubular stationary outer cutter with a port at its tip and a tubular inner cutter with a cutting surface coaxially disposed therein. The interior of the inner cutter is connected to a vacuum source. Irrigation fluid is provided at the surgical site through an infusion cap. C, D: Conventional vitrectomy uses either a rotational or a "guillotine-style" device. The rotational device has an inner cutter that cuts by rotating around its longitudinal axis (C), while the guillotine-style device has an inner cutter that cuts by longitudinal motion along its axis (D). (E) Comparison of the 20-, 23- and 25-G vitreous cutters. Both the 23-G and 25-G vitreous cutters have the cutter opening closer to the end of the tips than $20-\mathrm{G}$. 


\section{ASPIRATION AND INFUSION RATE}

The reason why the 25-G vitrector has a lower aspiration and infusion rate as compared to the 20-G cutter is due to its smaller port size and inner diameter [7]. Flow rates can be affected by various factors such as the type of the removed substance (fluid, blood clot, or proliferative tissue), cutting rate, and the internal diameter of the vitrector [13, 20, 21].

In general, a higher cutting rate allows less fluid and tissue to enter the port per cut [7, 19]. The constant duty cycle electric drive employs a constant balanced saline solution flow that results in an increased vitreous flow as the speed is increased, whereas there is a reduced duty cycle at high speeds with the pneumatic drive mechanism [20]. Since the vitreous flow rate tends to vary even among vitreous cutters with the same gauge size, cut rate, and vacuum, this suggests that flow rate can be affected by duty cycle performance, cutting port area, and the internal shaft diameter as shown in Table 2 [20-26].

Because of a small-sized opening with the $25-\mathrm{G}$ vitreous cutters, higher infusion and aspiration pressures are necessary to dissect the vitreous tissue. Typical settings for small-gauge vitrectomy are in the range of 1200 to $2500 \mathrm{cpm}, 35$ to $50 \mathrm{mmHg}$ for infusion, and up to $600 \mathrm{mmHg}$ for aspiration pressures [7, 27]. Furthermore, it is now possible to perform vitrectomies with cut rates up to $5000 \mathrm{cpm}$ with the newer vitrectomy system from Alcon. The new cutter of Alcon's Constellation system is activated by alternating air pulses to two chambers separated by a membrane. It provides higher cut rates with more reliable and adjustable duty cycle. Bausch \& Lomb also commercialized a new vitrectomy system with $5000 \mathrm{cpm}$ cut rate.

Table 2. Summary of commercial vitreous cutters by Hubschman [22, 23]

\begin{tabular}{|c|c|c|c|c|c|c|c|c|c|}
\hline \multirow[b]{3}{*}{$\begin{array}{l}\text { Vitreous Cutter } \\
\text { Model\# }\end{array}$} & \multirow[b]{3}{*}{ Vitrectomy Console } & \multirow{3}{*}{$\begin{array}{c}\text { Cutter } \\
\text { size } \\
\text { (Gauge) }\end{array}$} & \multirow[b]{3}{*}{$\begin{array}{l}\text { Vacuum } \\
(\mathrm{mmHg})\end{array}$} & \multirow{3}{*}{$\begin{array}{c}\text { Maximum } \\
\text { rate } \\
\text { (cuts/minute) }\end{array}$} & \multirow[b]{3}{*}{ Power } & \multirow{3}{*}{$\begin{array}{c}\text { Total } \\
\text { length } \\
(\mathrm{mm})\end{array}$} & \multicolumn{3}{|c|}{ Diameter of Shaft $(\mu \mathrm{m})$} \\
\hline & & & & & & & \multirow{2}{*}{$\begin{array}{c}\begin{array}{c}\text { External } \\
\text { Shaft }\end{array} \\
\text { External } \\
\text { diameter }\end{array}$} & \multicolumn{2}{|c|}{ Internal Shaft } \\
\hline & & & & & & & & $\begin{array}{c}\text { Inner } \\
\text { diameter }\end{array}$ & $\begin{array}{c}\text { Outer } \\
\text { diameter }\end{array}$ \\
\hline $\begin{array}{l}\text { Alcon* } \\
\# 8065740253\end{array}$ & Accurus $800^{*}$ & $20-\mathrm{G}$ & 250 & 2,500 & Pneumatic & 32.5 & 900 & 475 & 640 \\
\hline $\begin{array}{l}\text { Bausch \& Lomb } † \\
\text { \#CX5825 }\end{array}$ & Millennium $\dagger$ & $20-\mathrm{G}$ & 250 & 1,500 & Electric & 28.9 & $870 / 730$ & 400 & - \\
\hline $\begin{array}{l}\text { Bausch \& Lomb } \dagger \\
\text { \#DP4803 }\end{array}$ & Millennium $\dagger$ & $20-\mathrm{G}$ & 250 & 750 & Pneumatic & 28.5 & 880 & 441 & - \\
\hline $\begin{array}{l}\text { Midlabs } \\
\# 2540 \mathrm{E}\end{array}$ & Millenium $\dagger+\bullet \mathrm{AVE}$ & $20-\mathrm{G}$ & 250 & 2500 & Pneumatic & - & 910 & 510 & 650 \\
\hline $\begin{array}{l}\text { Alcon* } \\
\# 806570821\end{array}$ & Accurus $800^{*}$ & $23-\mathrm{G}$ & 550 & 2500 & Pneumatic & 30.6 & 630 & 355 & 460 \\
\hline $\begin{array}{l}\text { DORC } \ddagger \\
\# 1226 \text { NMD06 }\end{array}$ & Accurus $800^{*}$ & $23-\mathrm{G}$ & 550 & 2500 & Pneumatic & 32.5 & 590 & 410 & 490 \\
\hline $\begin{array}{l}\text { Alcon* } \\
\# 8065750220\end{array}$ & Accurus 800 & $25-\mathrm{G}$ & 550 & 1500 & Pneumatic & 31.6 & 500 & 227 & - \\
\hline $\begin{array}{l}\text { Bausch \& Lomb } \dagger \\
\text { \#CX5825 }\end{array}$ & $\dagger$ Millennium $\dagger$ & $25-\mathrm{G}$ & 550 & 1500 & Electric & 28.9 & 500 & 247 & - \\
\hline 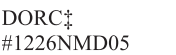 & Millenium $\dagger$ & $25-\mathrm{G}$ & 550 & 750 & Pneumatic & 28.8 & 490 & 291 & - \\
\hline $\begin{array}{l}\text { Midlabs§ } \\
\# 2540 \mathrm{E}\end{array}$ & Millenium $\dagger+\Phi \mathrm{AVE}$ & $25-\mathrm{G}$ & 550 & 2500 & Pneumatic & 28.4 & 500 & 292 & 370 \\
\hline
\end{tabular}

*Alcon Surgical, Forth Worth, TX, USA.

${ }^{\dagger}$ Storz Millennium Microsurgical System, Bausch \& Lomb, St Louis, MO, USA.

‡Dutch Ophthalmic USA, Kingston, NH, USA.

${ }^{\S}$ Midlabs, San Leandro, CA, USA.

IStorz Millennium Microsurgical System, Bausch \& Lomb, in association with the AVE 2500 P module, Medical Instrument Development Labs Inc. (Midlabs). 


\section{CUTTING PORT AND SHAFT}

The size and position of the cutting port also affect the flow and aspiration efficiency. The sizes of the ports in the $23-\mathrm{G}$ and $25-\mathrm{G}$ cutter are smaller than that of Alcon's 20$\mathrm{G}$ probe (56\% versus $31 \%$, respectively; see Figure $4 \mathrm{E})$. The smaller port size combined with the higher cutting rates for the $25-\mathrm{G}$ cutter results in a lower aspiration; therefore, the 25-G cutter is safer for peripheral vitreous dissection closer to the retina. As compared to the $20-\mathrm{G}$ cutter, the port of the $25-\mathrm{G}$ cutter is closer to the tip. This facilitates peripheral shaving of the vitreous base and segmentation or delamination of the proliferative tissue.

Due to the small size, the $23-\mathrm{G}$ and $25-\mathrm{G}$ cutters are less stiff than that of the $20-\mathrm{G}$ probe [22]. Hubschman et al. reported that even within the same gauge group, the cutter rigidity varies due to the differences in the metal properties, thickness of the shaft wall, and length of the cutter [22]. Although stiffness is improved by reducing the cutter length, short cutters are not suited for highly myopic eyes that are axially long. Rigid vitreous instruments are important in dissecting proliferative tissue, shaving peripheral vitreous, and removing dislocated intraocular lenses. Low rigidity can pose a serious problem, particularly with the thin $27-\mathrm{G}$ probe. After Oshima et al. shortened Alcon's $25-\mathrm{G}$ shaft from $32 \mathrm{~mm}$ to $25 \mathrm{~mm}$, they succeeded in creating a $27-\mathrm{G}$ cutter that had a shaft rigidity similar to the $25-\mathrm{G}$ cutter [11]. By shortening the shaft, they were able to successfully perform peripheral vitrectomy using the $27-\mathrm{G}$ system in eyes with axial lengths ranging from 22 to $28 \mathrm{~mm}$.

\section{ILLUMINATION}

In the early 1970s, an external slit illuminator outside the eye was first employed in vitrectomy. To facilitate the insertion of a fiber optic light source inside the eye, Peyman developed a prototype illumination device for a three-port vitrectomy in 1976 [28]. The subsequent development of a small-diameter wide-angle endoillumination probe enabled a wide panoramic view of the surgical area $[29,30]$. In the $20-\mathrm{G}$ vitrectomy system, a halogen light source was commonly used for illumination, while the halogen light used in the $25-\mathrm{G}$ system had about $40 \%$ of the brightness of the $20-\mathrm{G}$ system.

In 2003, Eckardt developed a xenon-based chandelier illumination probe, which was designed to directly penetrate the conjunctiva and sclera [31]. As the xenon light source is now brighter than the regular halogen light, illumination is no longer an issue in the 25-G system (Figure 5). Recently, several other xenon illuminators such as Xenon (Alcon Labs., Fort Worth, TX), Photon (Synergetics Inc., O'Fallon, MO), and BrightStar (DORC, Zuidland, The Netherlands) have been developed. Alcon's new Constellation system provides a much brighter illumination than the original Xenon light. Upon the development of the 27-G vitrectomy, Eckardt et al. developed the 27-G illumination system in 2008 [32], while Oshima et al. in the same year also developed the 27-G and 29-G illumination system [10,33]. Subsequently, Synergetics released a much brighter mercury vapor lamp (Photon 2, Synergetics), while Oshima et al. further developed a 29-G mercury-vapor illuminator which emitted light twice as bright as the 29-G xenon-based probe [33]. 

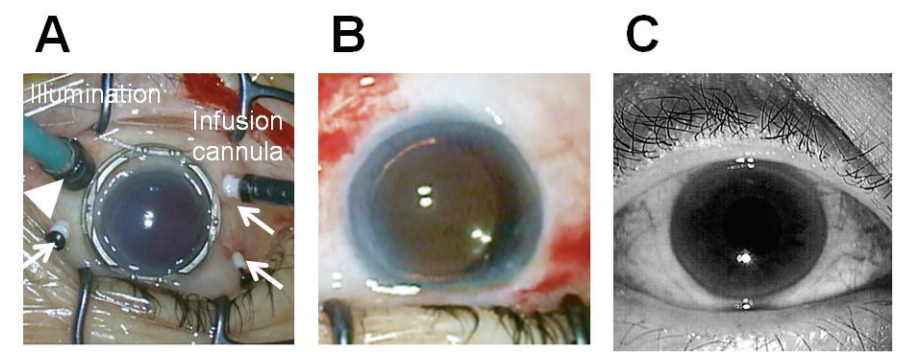

Figure 5. External photographs of a right eye undergoing a transconjunctival vitrectomy procedure using a disposable $25-\mathrm{G}$ device. (A) The three ports for infusion (indicated by arrows) allow for easy access to the peripheral vitreous and retina. A chandelier illumination is placed inferiorly to allow for adequate visualization of the posterior segment (indicated by triangular arrow head, upper left). (B) All three microcannulas, including the infusion line and illumination, were removed without the need for suture after the vitrectomy. (C) One week after the vitrectomy, no leakage or bleeding is visible.

\section{OTHER INSTRUMENTATION AND MATERIALS}

In the last decade, other surgical instruments and innovations have been developed including a vitrectomy system that uses endoscopic visualization, a wide-field viewing system, and an endolaser system. Surgical materials such as perfluorocarbon liquid, silicone oil, perfluoropropane (C3F8) gas, and sulfur hexafluoride (SF6) gas have also been developed and applied as vitreous tamponades in the severe cases involving retinal detachment and proliferative vitreoretinopathy. To enhance the visualization of the vitreous, epiretinal membrane, and the internal limiting membrane, various staining agents have been employed including indocyanine green (ICG) [34-37], trypan blue (TB) [35-40], triamcinolone acetonide (TA) [41], and brilliant blue G (BBG) [42, 43].

\section{COMPLICATIONS}

The self-sealing nature of the sutureless $25-\mathrm{G}$ vitrectomy increased the rate of postoperative complications such as vitreous incarceration, wound leakage, hypotony, retinal traction, and bacterial endophthalmitis [44-46]. The most devastating complication has been bacterial endophthalmitis. Several large, multicenter, comparative studies have estimated the incidence of postoperative endophthalmitis after 25-G PPV to be $0.23-0.84 \%$ [47-48]. Kunimoto et al. reported that endophthalmitis developed in 7 of 3103 eyes $(0.23 \%)$ after 25-G PPV and in 1 of 5498 eyes $(0.018 \%)$ after $20-\mathrm{G}$ PPV $(\mathrm{P}=0.004)$ [47]. Similarly, Scott et al. reported that endophthalmitis developed in 11 of 1,307 eyes $(0.84 \%)$ after $25-\mathrm{G}$ PPV and in 2 of 6,375 eyes $(0.03 \%)$ after $20-\mathrm{G} P P V(\mathrm{P}<0.0001)$ [48]. Overall, the results translate to a 12- to 28-fold higher risk of endophthalmitis associated with 25-G PPV than 20-G PPV.

Contrary to the reports above, four other studies showed that there were no significant statistical differences in the incidence of endophthalmitis between 20-G and 
25-G PPV [49-52]. Shimada et al. reported postoperative endophthalmitis in 1 of 3592 eyes $(0.0278 \%)$ after $20-\mathrm{G}$ vitrectomies and in 1 of 3343 eyes $(0.0299 \%)$ after $25-\mathrm{G}$ vitrectomies, with no statistically significant difference [49]. Similarly, Mason et al. found no significant difference in the event rate of endophthalmitis between the two methods, with endophthalmitis in only 1 of 1,906 eyes (0.053\%) after $25-\mathrm{G}$ PPV and in 2 of 2,642 eyes $(0.076 \%)$ after $20-\mathrm{G}$ PPV $(\mathrm{P}=1)$ [50]. $\mathrm{Hu}$ et al. observed endophthalmitis in 1 of 1424 eyes $(0.07 \%)$ from the 25-G PPV group and in none of 1948 eyes $(0 \%)$ in the $20-\mathrm{G}$ group $(\mathrm{P}=0.42)$ [51]. Chen et al. also reported endophthalmitis in 1 of 431 eyes $(0.23 \%)$ after $25-\mathrm{G}$ PPV and 1 of 3046 eyes $(0.03 \%)$ after 20-G PPV $(\mathrm{P}=0.23)$ [52]. Analyses of postoperative endophthalmitis event rates after combined phacoemulsification cataract surgery and PPV were 1 of 46 eyes (2.17\%) for 25-G PPV and 0 of 170 eyes $(0 \%)$ for $20-G$ PPV $(P=0.21)$ [52].

Recently, Scott et al. examined the endophthalmitis rates between $20-\mathrm{G}, 23-\mathrm{G}$ and 25-G PPV during the period of 2007-2008, and compared the rates with those found during 2005-2006 [53]. There results indicated that the endophthalmitis incidence during 2007-2008 was 1 of 4,403 eyes (0.02\%) for 20-G PPV, 1 of 3,362 eyes (0.03\%) for $23-\mathrm{G}$ PPV, and 1 of 789 eyes $(0.13 \%)$ for $25-\mathrm{G}$ PPV. There were no significant differences among these rates between any two of the three groups. When the endophthalmitis rates were compared among the same group of surgeons during the 2005-2006 period, the 2007-2008 endophthalmitis rates after 20-G and 23-G PPV were stable, while the rates after 25-G PPV were marginally lower $(\mathrm{P}=0.056$; odds ratio $=$ 0.15 ; $95 \%$ CI: $(0.003,1.03))$. The reduction in the incidence of endophthalmitis after 25-G PPV to levels close to those after 20-G PPV may be due to improvements in instrumentation, surgical technique, wound construction, or case selection, as well as the experience of the surgeons. In our study of 500 consecutive patients who recently underwent 25-G PPV at our medical center, there were no patients who developed endophthalmitis postoperatively.

It was suggested that the potential risk factors of endophthalmitis following smallgauge PPV may include wound leakage, postoperative hypotony, less vigorous flow through the 25-G infusion, vitreous herniation, use of intravitreal injection of triamcinolone acetonide, absence of subconjunctival antibiotics, patient-induced wound distortion, or a history of diabetes or other immunosuppressive disease [47, 48, 53].

Based on both the published literature and our own experience, we can reasonably conclude that various procedures such as preoperative preventive disinfection with povidone-iodine, conjunctival displacement with beveled cannula insertion, complete removal and shaving of the vitreous, reduction of vitreous incarceration and wound leakage by covering the conjunctiva or suturing the sclerotomy site, and the injection of subconjunctival antibiotics at the end of surgery may all lead to a reduction in the incidence of endophthalmitis [47, 54]. When the 25-G PPV method was first introduced, it was publicized as being an easy and less complicated sutureless PPV procedure. The term "sutureless PPV" may be misleading as in fact suturing is required to close the wound. Thus, if there is wound leakage, there should be no hesitation regarding the placement of a suture to close the wound. By pursuing prudent treatments, this will help to reduce the risk of endophthalmitis. 


\section{CONCLUSION}

This review has highlighted some of the latest innovations in vitreous surgery. In recent years, significant advances have been made in the development of small-gauge PPV systems. These systems have expanded the surgical indications and have led to improved treatment of severe vitreoretinal diseases including tractional retinal detachments and proliferative vitreoretinopathy. We believe that small-gauge PPV procedures contribute to safe and effective treatment of a variety of retinal diseases, as they can reduce surgical time, postoperative inflammation, postoperative corneal astigmatism, and patient discomfort, and they can further provide a faster postoperative visual recovery. The sutureless small-gauge PPV is already an integral part of modernday vitreous surgery, and will continue to make an impact on the management of vitreoretinal disease.

\section{CONFLICT OF INTEREST: None.}

\section{REFERENCES}

[1] Machemer, R. A new concept for vitreous surgery. 2. Surgical technique and complications. Am J Ophthalmol, 1972, 74(6), 1022-1033.

[2] Machemer, R. and Norton, E.W. A new concept for vitreous surgery. 3. Indications and results. Am J Ophthalmol, 1972, 74(6), 1034-1056.

[3] O'Malley, C. and Heintz, R.M. Sr. Vitrectomy with an alternative instrument system. Ann Ophthalmol, 1975, 7(4), 585-588, 591-594.

[4] De Juan, E. Jr. and Hickingbotham, D. Refinements in microinstrumentation for vitreous surgery. Am J Ophthalmol, 1990, 109(2), 218-220.

[5] Hilton, G.F., Josephberg, R.G., Halperin, L.S., Madreperla, S.A., Brinton, D.A., Lee, S.S. and Gordon, S.F. Office-based sutureless transconjunctival pars plana vitrectomy. Retina, 2002, 22(6), 725-732.

[6] Eckardt, C. Transconjunctival sutureless 23-gauge vitrectomy. Retina. 2005, 25(2), 208-211.

[7] Fujii G.Y., De Juan, E. Jr., Humayun, M.S., Pieramici, D.J., Chang, T.S., Awh, C., Ng, E., Barnes, A., Wu. S.L. and Sommerville, D.N. A new 25-gauge instrument system for transconjunctivalsutureless vitrectomy system for vitreoretinal surgery Ophtahlmology, 2002, 109(10), 1807-1812; discussion 1813.

[8] Fujii, G.Y., De, Juan, E. Jr, Humayun, M.S., Chang, T.S., Pieramici, D.J., Barnes, A. and Kent, D. Initial experience using the transconjunctival sutureless vitrectomy system for vitreoretinal surgery. Ophthalmology, 2002, 109(10), 1814-1820.

[9] Au, Eong, K.G., Fujii, G.Y., De, Juan, E. Jr., Jensen, P.S., Sommerville, D.N., Shelley, T.H., Barnes, A.C. and Maia, M. A new three-port cannular system for closed pars plana vitrectomy. Retina, 2002, 22(1), 130-132.

[10] Oshima, Y., Awh, C.C. and Tano, Y. Self-retaining 27-gauge transconjunctival chandelier endoillumination for panoramic viewing during vitreous surgery. Am J Ophthalmol, 2007, 143(1), 166-167.

[11] Oshima, Y., Wakabayashi, T., Sato, T., Ohji, M. and Tano, Y. A 27-gauge instrument system for transconjunctival sutureless microincision vitrectomy surgery. Ophthalmology, 2010, 117(1), 93-102.

[12] Chen, E. 25-Gauge transconjunctival sutureless vitrectomy. Curr Opin Ophthalmol, 2007, 18(3), 188-193.

[13] Warrier, S.K., Jain, R., Gilhotra, J.S. and Newland, H.S. Sutureless vitrectomy. Indian J Ophthalmol, 2008, 56(6), 453-458.

[14] Spirn, M.J. Comparison of 25, 23 and 20-gauge vitrectomy. Curr Opin Ophthalmol, 2009, 20(3), 195-159. 
[15] Sandinha, T., de, Souza, C., Essex, R., Kelly, T.L., Lake, S. and Phillips R. Revisiting transconjunctival sutureless 25-gauge vitrectomy: still worthwhile? Clin Experiment Ophthalmol, 2009, 37(7), 649-653.

[16] Recchia, F.M., Scott, I.U., Brown, G.C., Brown, M.M., Ho, A.C. and Ip, M.S. Small-gauge pars plana vitrectomy: a report by the American Academy of Ophthalmology. Ophthalmology, 2010, 117(9). 1851-1857.

[17] Fabian, I.D. and Moisseiev, J. Sutureless vitrectomy: evolution and current practices. Br J Ophthalmol, 2011, 95(3), 318-24.

[18] Cleary, P.E. The treatment of advanced diabetic eye disease. Ir J Med Sci, 1979, 148(Suppl 2), 38-44.

[19] McCary, B.D, Daniel, C.S. and Edwards, K.H. System enhancements bring added safety, efficiency and ease-of-use to 25-gauge vitrectomy. Bausch \& Lomb Incorporated, SU4024, 2004.

[20] Magalhaes O Jr, Chong L, DeBoer C, Bhadri P, Kerns R, Barnes A, Fang S, Humayun M. Vitreous dynamics: vitreous flow analysis in 20-, 23-, and 25-gauge cutters. Retina. 2008;28(2):236-241.

[21] Magalhães, O. Jr., Maia, M., Maia, A., Penha, F., Dib, E., Farah, M.E. and Schor, P. Fluid dynamics in three 25-gauge vitrectomy systems: principles for use in vitreoretinal surgery. Acta Ophthalmol 2008, 86(2), 156-159.

[22] Hubschman, J.P., Gupta, A., Bourla, D.H., Culjat, M., Yu, F. and Schwartz, S.D. 20-23-, and 25-gauge vitreous cutters: performance and characteristics evaluation. Retina, 2008, 28(2), 249-257.

[23] Hubschman, J.P., Bourges, J.L., Tsui, I., Reddy, S., Yu, F. and Schwartz, S.D. Effect of cutting phases on flow rate in 20-, 23-, and 25-gauge vitreous cutters. Retina, 2009, 29(9), 1289-1293.

[24] Fang, S.Y., Deboer, C.M. and Humayun, M.S. Performance analysis of new-generation vitreous cutters. Graefes Arch Clin Exp Ophthalmol, 2008, 246(1), 61-67.

[25] Sato, T., Kusaka, S., Oshima, Y. and Fujikado, T. Analyses of cutting and aspirating properties of vitreous cutters with high-speed camera. Retina, 2008, 28(5), 749-754.

[26] Teixeira, A., Chong, L.P., Matsuoka, N., Arana, L., Kerns, R., Bhadri, P. and Humayun, M. Vitreoretinal traction created by conventional cutters during vitrectomy. Ophthalmology, 2010, 117(7), 1387-1392.e2.

[27] Altan, T., Acar, N., Kapran, Z., Unver, Y.B. and Ozdogan, S. Transconjunctival 25-gauge sutureless vitrectomy and silicone oil injection in diabetic tractional retinal detachment. Retina, 2008, 28(9), 1201-1206.

[28] Peyman, G.A. Improved vitrectomy illumination system. Am J Ophthalmol, 1976, 81(1), 99-100.

[29] Ryan, E.H. Jr. Two shielded 'bullet' probes for panoramic endoillumination. Arch Ophthalmol, 1997, 115(1), 125-126.

[30] Peyman, G.A., Canakis, C., Livir-Rallatos, C. and Easley, J. A new wide-angle endoillumination probe for use during vitrectomy. Retina, 2002, 22(2), 242.

[31] Eckardt, C. Twin lights: a new chandelier illumination for bimanual surgery. Retina, 2003, 23(6), 893-894.

[32] Eckardt, C., Eckert, T. and Eckardt, U. 27-gauge Twinlight chandelier illumination system for bimanual transconjunctival vitrectomy. Retina, 2008, 28(3), 518-519.

[33] Oshima, Y., Chow, D.R., Awh, C.C., Sakaguchi, H. and Tano, Y. Novel mercury vapor illuminator combined with a 27/29-gauge chandelier light fiber for vitreous surgery. Retina, 2008, 28(1), 171-173.

[34] Sorcinelli, R. Surgical management of epiretinal membrane with indocyanine-green-assisted peeling. Ophthalmologica, 2003, 217(2), 107-110.

[35] Kwok, A.K., Lai, T.Y., Li, W.W., Woo, D.C. and Chan, N.R. Indocyanine green-assisted internal limiting membrane removal in epiretinal membrane surgery: a clinical and histologic study. Am J Ophthalmol, 2004, 138(2), 194-199.

[36] Kwok, A.K., Lai, T.Y., Li, W.W., Yew, D.T. and Wong, V.W. Trypan blue- and indocyanine greenassisted epiretinal membrane surgery: clinical and histopathological studies. Eye (Lond), 2004, 18(9), 882-888. 
[37] Kwok, A.K., Lai, T.Y. and Yuen, K.S. Epiretinal membrane surgery with or without internal limiting membrane peeling. Clin Experiment Ophthalmol, 2005, 33(4), 379-385.

[38] Gibran, S.K., Flemming, B., Stappler, T., Pearce, I., Groenewald, C., Heimann, H., Hiscott, P. and Wong, D. Peel and peel again. Br J Ophthalmol, 2008, 92(3), 373-377.

[39] Haritoglou, C., Gandorfer, A., Schaumberger, M., Priglinger, S.G., Mueller, A.J., Gass, C.A. and Kampik, A. Trypan blue in macular pucker surgery: an evaluation of histology and functional outcome. Retina, 2004, 24(4), 582-590.

[40] Haritoglou, C., Eibl, K., Schaumberger, M., Mueller, A.J., Priglinger, S., Alge, C. and Kampik, A. Functional outcome after trypan blue-assisted vitrectomy for macular pucker: a prospective, randomized, comparative trial. Am J Ophthalmol, 2004, 138(1), 1-5.

[41] Tognetto, D., Zenoni, S., Sanguinetti, G., Haritoglou, C. and Ravalico, G. Staining of the internal limiting membrane with intravitreal triamcinolone acetonide. Retina 2 2005, 25(4), 462-467.

[42] Enaida, H., Hisatomi, T., Hata, Y., Ueno, A., Goto, Y., Yamada, T., Kubota, T. and Ishibashi, T. Brilliant blue $\mathrm{G}$ selectively stains the internal limiting membrane/brilliant blue Gassisted membrane peeling. Retina, 2006, 26(6), 631-636.

[43] Shimada, H., Nakashizuka, H., Hattori, T., Mori, R., Mizutani, Y. and Yuzawa, M. Double staining with brilliant blue $\mathrm{G}$ and double peeling for epiretinal membranes. Ophthalmology, 2009, 116(7), 1370-1376.

[44] Meyer, C.H., Rodrigues, E.B., Schmidt, J.C., Horle, S. and Kroll, P. Sutureless vitrectomy surgery. Ophthalmology, 2003, 110(12), 2427-2428.

[45] Lam, D.S., Yuen, C.Y., Tam, B.S., Cheung, B.T. and Chan, W.M. Sutureless vitrectomy surgery. Ophthalmology, 2003, 110(12), 2428-2429.

[46] Ibarra, M.S., Hermel, M., Prenner, J.L. and Hassan, T.S. Longer-term outcomes of transconjunctival sutureless 25-gauge vitrectomy. Am J Ophthalmol 2005, 139(5), 831-836.

[47] Kunimoto, D.Y. and Kaiser, R.S. Incidence of endophthalmitis after 20- and 25-gauge vitrectomy. Ophthalmology, 2007, 114(12), 2133-2137.

[48] Scott, I.U., Flynn, H.W. Jr., Dev, S., Shaikh, S., Mittra, R.A., Arevalo, J.F., Kychenthal, A. and Acar, N. Endophthalmitis after 25-gauge and 20-gauge pars plana vitrectomy: incidence and outcomes. Retina, 2008, 28(1), 138-142.

[49] Shimada, H., Nakashizuka, H., Hattori, T., Mori, R., Mizutani, Y. and Yuzawa, M. Incidence of endophthalmitis after 20- and 25-gauge vitrectomy causes and prevention. Ophthalmology, 2008, 115(12), 2215-2220.

[50] Mason, J.O. 3rd., Yunker, J.J., Vail, R.S., White, M.F. Jr., Feist, R.M., Thomley, M.L., Albert, M.A. Jr. and Persaud, T.O. Incidence of endophthalmitis following 20-gauge and 25-gauge vitrectomy. Retina, 2008, 28(9), 1352-1354.

[51] Hu, A.Y., Bourges, J.L., Shah, S.P., Gupta, A., Gonzales, C.R., Oliver, S.C. and Schwartz, S.D. Endophthalmitis after pars plana vitrectomy: a 20- and 25-gauge comparison. Ophthalmology, 2009, 116(7), 1360-1365.

[52] Chen, J.K., Khurana, R.N., Nguyen, Q.D. and Do, D.V. The incidence of endophthalmitis following transconjunctival sutureless 25- vs 20-gauge vitrectomy. Eye (Lond), 2009, 23(4), 780-784.

[53] Scott, I.U., Flynn, H.W. Jr., Acar, N., Dev, S., Shaikh, S., Mittra, R.A., Arevalo, J.F., Kychenthal, A. and Kunselman, A. Incidence of endophthalmitis after 20-gauge vs 23-gauge vs 25-gauge pars plana vitrectomy. Graefes Arch Clin Exp Ophthalmol, 2011, 249(3), 377-380.

[54] Farouk, M.M., Naito, T., Sayed, K.M., Nagasawa, T., Katome, T., Radwan, G., Abdallah, A. and Elagouz, M. Outcomes of 25-gauge vitrectomy for proliferative diabetic retinopathy. Graefes Arch Clin Exp Ophthalmol, 2011, 249(3), 369-376. 


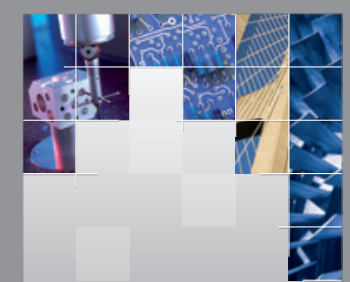

\section{Enfincering}
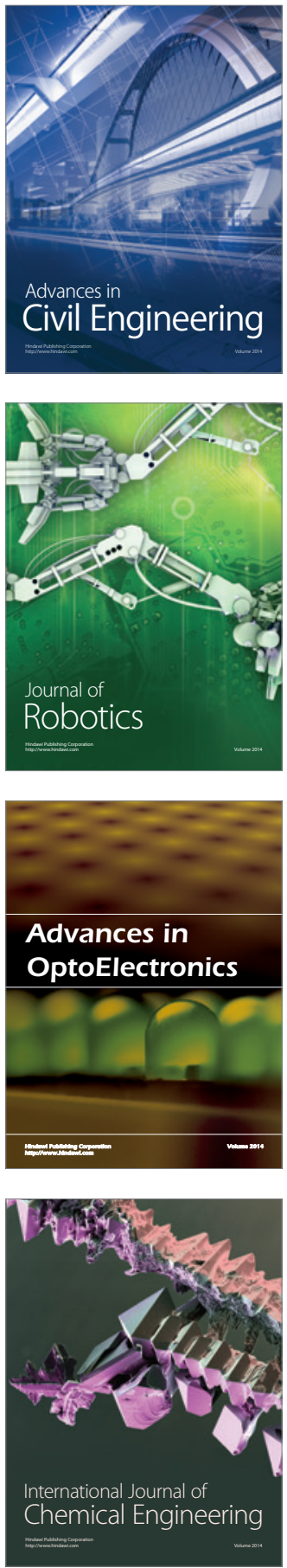

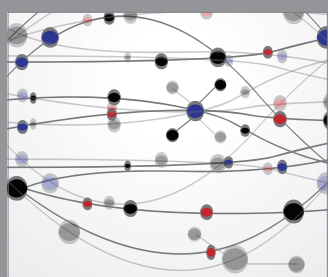

The Scientific World Journal

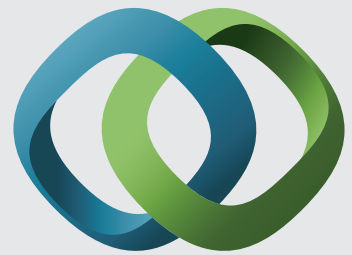

\section{Hindawi}

Submit your manuscripts at

http://www.hindawi.com
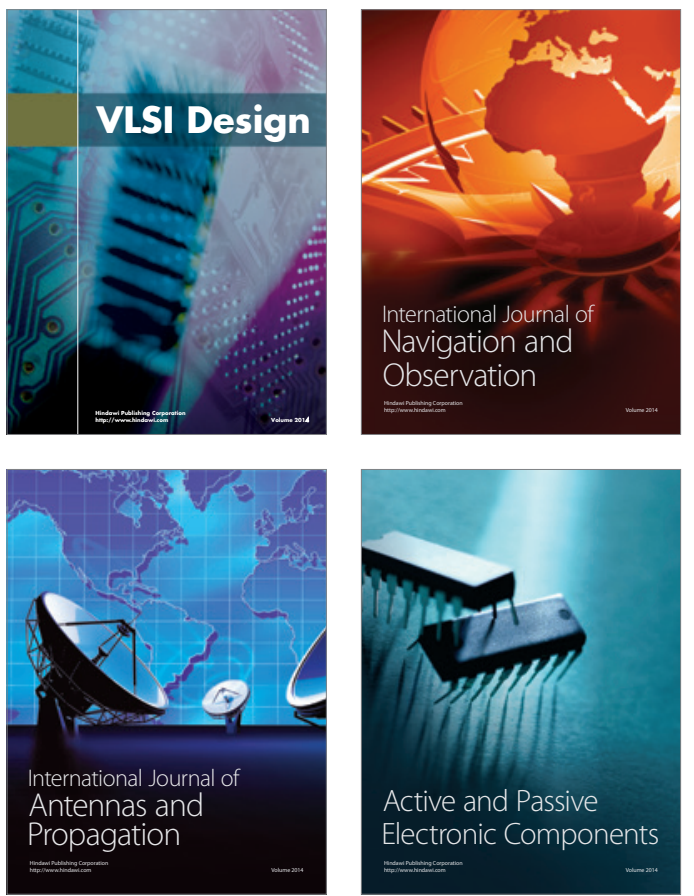
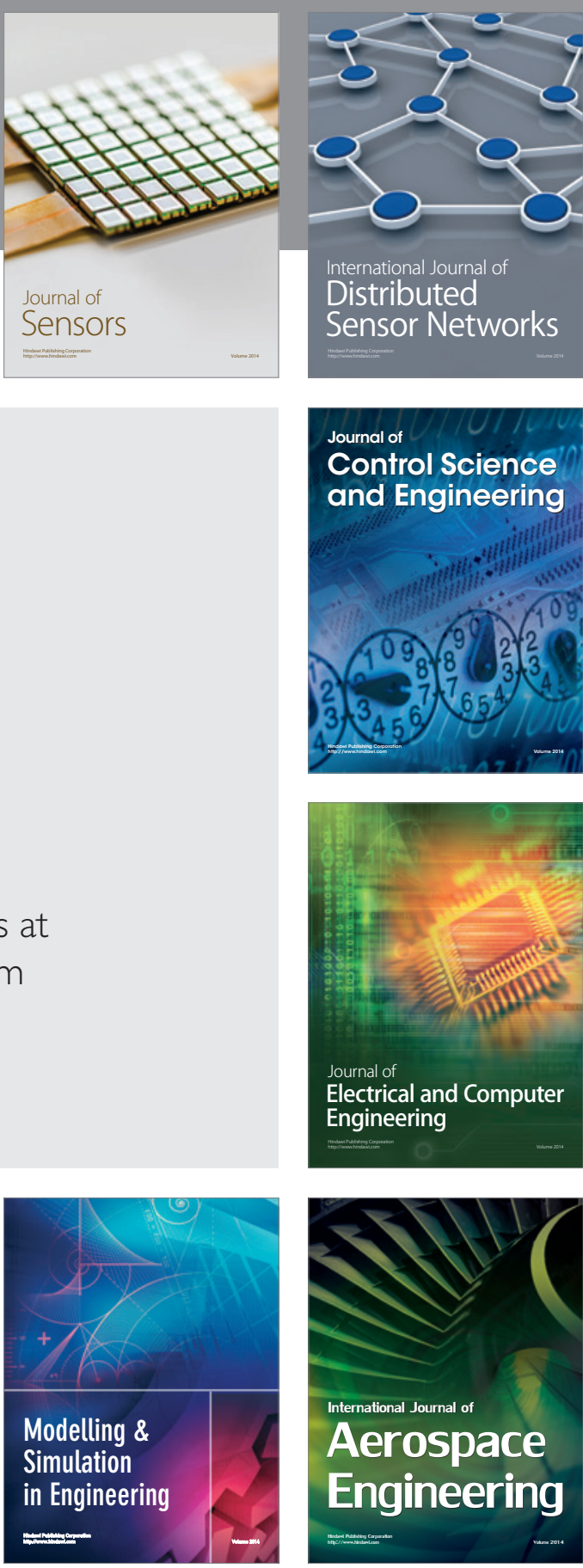

International Journal of

Distributed

Sensor Networks

Journal of

Control Science

and Engineering
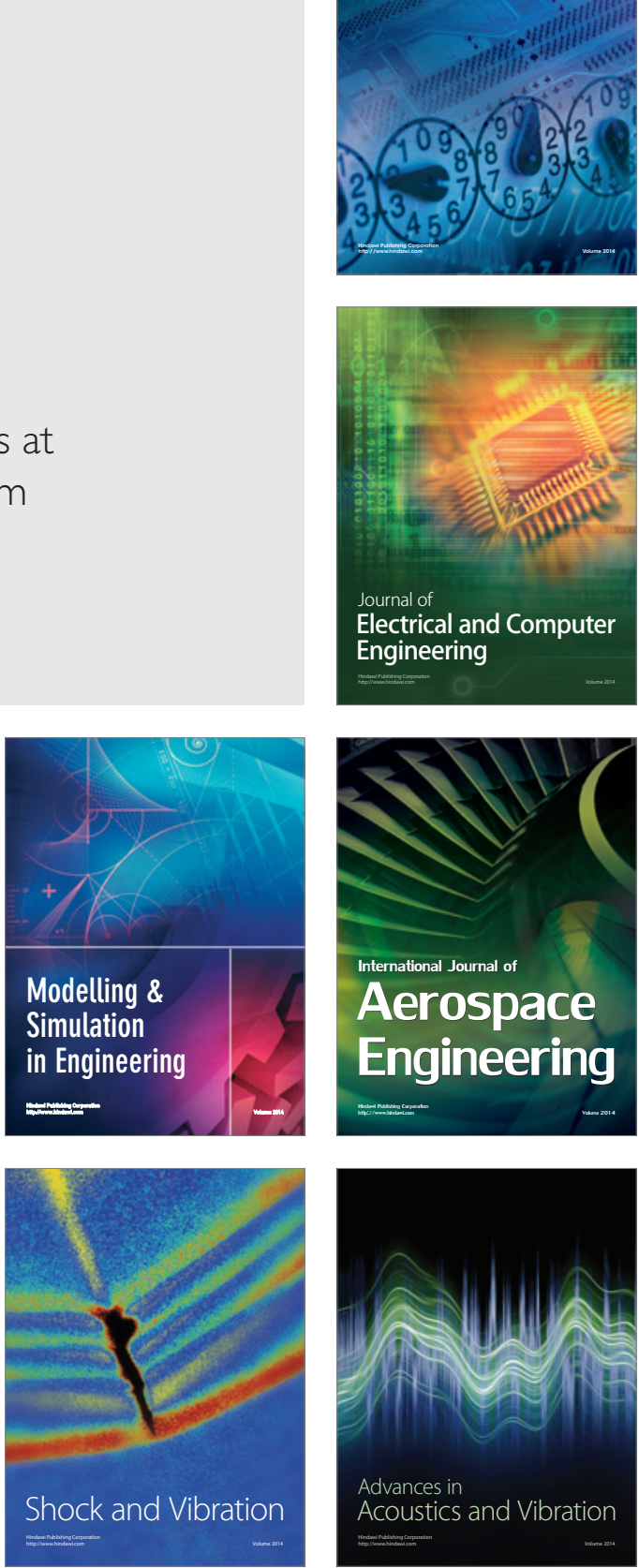